\title{
UNNATURAL SELECTION: CHOOSING BOYS OVER GIRLS, AND THE CONSEQUENCES OF A WORLD FULL OF MEN
}

\author{
Mara Hvistendahl* (2011), New York: Public Affairs, \\ 314 sayfa, ISBN: 1610391519
}

Hvistendahl kitabın önsözüne şu cümleyle başlıyor:

"Bir zamanlar Mao Ze Dung, "Gökyüzünün yarısını kadınlar taşıyor" demişti ve Çin'e taşınıncaya kadar ben de buna inanıyordum" (s. xi).

Mara Hvistendahl'1 2012 Pulitzer ödülü finalisti yapan bu kitap, başarılı bir araştırmacı gazetecilik örneği olmasının yanında akademik özgünlükler taşıyan, detaylı ve titiz bir çalışma olarak ortaya çıkmaktadır. Kitap Çin örneğinde somutlaşmış bir "kadını yok sayma ve yok etme" anlayışının ve pratiklerinin yarattığı geri dönüşü olmayan sonuçlar üzerinde çarpıcı ve düşündürücü bir içerik sunmaktadır. Derecesi toplumsal ve ekonomik gelişmişlik düzeyine bağlı olarak, hemen hemen her toplumda kadını yok saymaya yönelik kültürel değerler yaşatılmakta ve mağduriyet yaşayan kadınların sayısı giderek artmaktadır. Yazar başta kadın mağdurlar olmak üzere, insan tacirleri, bilim insanları, aktivistler gibi kişilerin deneyimlerinden alıntılarla bu konuda gerçek bir hikaye anlatmaktadır. Kitap gerek disiplinler arası yaklaşımı gerekse eleştirel bakışıyla basın, kamu, bilim ve teknoloji ile sanayi otoriteleri tarafından ilgiyle karşılanmış, Economist, The Financial Times, New York Times vb. gazeteler yanında çeşitli dergilerde, toplantılarda tanıtılmış, yazarla çeşitli söyleşiler yapılmıştır.

* Mara Hvistendahl, Columbia Üniversitesi Gazetecilik bölümü mezunudur ve Atlantic, The Wall Street Journal, Popular Science, Foreign Policy gibi kuruluşlarda çalışmıştır. Yaşamının bir bölümünü Çin'de geçirmiş olması yazarın Mandarin diline hakim olmasını sağlamış, ileride yapacağı çalışmalara zemin oluşturacak toplumsal yaşamla ilgili gözlemleri de belirli konulara odaklanması için firsatlar sunmuştur. Shangai Science Dergisi editörü olarak da çalışan yazar, Çin toplumuyla ilgili çeşitli araştırmalar yapmış ve makaleler yazmıştır. 2008 yılında yayınlanmış "The City Swallowed Them" adlı bir kitabı da bulunan yazar, halen ABD'de Science Dergisi'nde çalışmaktadır. 
Hvistendal, Çin üniversitelerinden birinde Mandarin dili kursu alırken yapmış olduğu bir çocuk yuvası ziyaretinin kendisini bu araştırmaya nasıl yönlendirdiğini şu anekdotla aktarmaktadır:

“...(ziyaretten) hatırladığım (tek) şey çocuk yuvasının nüfusu ve bize hoş geldin diyen küçük gülümseyişler denizinde oğlanların kızlardan sayıca üstün olduğu (idi)... Üniversiteye geri dönerken Tsang adlı öğretmenim Çince olarak o güne kadar duymadığım bir sözcük telaffuz etti: Ultrason... Batıdan ithal edilen...(diyordu) Anlamıştım. Bazı kadınlar hamileliklerinin ortasına yaklaşırken ultrason taramasına giriyor ve eğer cenin kızsa düşük (kürtaj) yap(tır)ıyordu” (s.xii).

Yazar, Charles Darwin'in günümüzde de hala tartışma odağı olan "doğal elenme" kuramına gönderme yapan başlı̆g ile kitabı eline alan okuru daha ilk satırında meraka ve düşünmeye sevk etmektedir. Araştırma, "Şimdi herkesin bir oğlu var", "Büyük bir fikir" ve "Kadınsız dünya" başlıklı üç ana bölümden oluşmakta, her bir bölüm de yine farklı başlıklar taşıyan çeşitli alt başlıklara ayrılmaktadır. Örneğin, birinci başlık altında nüfusbilimcilerin, ebeveynlerin, iktisatçıların, tıp doktorlarının ve emperyalistlerin konuyla ilgili yaklaşımları, rolleri ve sorumlulukları ele alınmaktadır. İkinci başlık altında tıbbi uzmanlar, genetikçiler, siyasetçiler ve askerler ile feministlerin görüşleri yer alırken, üçüncü başlık altında ithal gelinler, fahişeler, bekârlar gibi alt başlıklarla mevcut durumun ortaya çıkardığ 1 istenmeyen sosyo-ekonomik ve kültürel sonuçlar gözler önüne serilmektedir.

Hvistendahl, öncelikle Nüfusbilim disiplininin açıklamalarını irdelemekte ve okuyucuyu tartışma konusuna yönlendirmektedir. Nüfusbilimciler ortalama olarak dünyada her 105 oğlan bebeğe karş1lık 100 kız bebek doğduğunu ve bunun "doğumda normal cinsiyet dağılım oranı" olarak kabul edildiğini ifade ediyorlar. Kuşkusuz bu oranlar ülkelerin gelişmişlik düzeylerine, kültürel özelliklerine ve bulundukları coğrafyaya göre değişebiliyor. Yazar kadın nüfusunun sadece büyük nüfuslu Çin ve Hindistan gibi Asya ülkelerinde değil, daha az nüfuslu Güney Kore, Tayvan ve Singapur'un bir bölümünde de doğum öncesi tarama teknikleri kullanımı yöntemiyle, erkekler lehine ciddi biçimde silindiğini ileri sürmektedir. Üstelik bu yalnız Asya’ya özgü bir durum da değildir. Kafkaslar bölgesi, Azerbaycan, Gürcistan, Ermenistan gibi Doğu Avrupa ve hatta Arnavutluk gibi Balkan ülkelerinde de kadın nüfusunun benzer yollarla azaltılması söz konusudur. Örneğin, 1980'de Güney Kore, Tayvan, Singapur'un bir bölümünde bu oran 109'u bulmaktaydı. 2010'da doğumda cinsiyet oranı Hindistan'da 112 Çin'de ise 121 olarak kaydedilmiştir. Yazar Asya'da bu yolla 160 milyon kız bebeğin yok edilerek "kadınların silindiğini" ifade etmektedir. 
Yazarın rakamlarla ortaya koymuş olduğu ve dünya nüfusundaki cinsiyet dağılımında bölgesel anormalliği vurgulayan araştırmasının içeriği ile uyumlu çok sayıda yayın ve belgesel de bulunmaktadır. Bunlar arasında Amitai Etzioni'nin "Cinsiyet Kontrolü, Bilim ve Toplum" $(1968)^{1}$ başlıklı makalesine yer verilmektedir. Etzioni çalışmasında cinsiyet kontrolünün ebeveynlere kız veya erkek çocuk seçimi vaat edişinin toplumda yol açabileceği cinsiyet dengesizliğine ve bunun olumsuz sonuçlarına dikkat çekiyordu. Amartya Sen'in "100 Milyon Kadından Fazlası Kayboluyor" (1990)² başlıklı çalışması da toplumsal cinsiyet ayrımcılığının olumsuz sonuçlarını işaret etmekteydi. Sen, bu durumu iktisadi olarak açıklamanın mümkün olmadığını, çünkü Hindistan'da varlıklı ailelerin yoksullara göre daha fazla erkek çocuk sahibi olmasının ancak ataerkil toplumsal değerlerin incelenmesiyle açıklanabileceğini vurgulamaktadır. $\mathrm{Bu}$ araştırmadaki iddiaları destekleyen belgeseller de bulunmaktadır: Shadowline tarafindan hazırlanan "O Bir Kiz!" $(2011)^{3}$ başlıklı Hindistan'la ilgili bir belgeselde, kız bebeklerin doğumdan sonra kutu içinde terk edildikleri daha da kötüsü öldürüldükleri anlatılmaktadır. Nitekim Hintli bir kadın $8 \mathrm{kız}$ bebeğini nasıl yok ettiğini anlatırken, Hvistendahl'ın ortaya koyduğu 163 milyon kız bebeğin doğmadan yok edildiği bilgisi inanılmaz olmanın ötesinde, korkutucu görünmektedir.

Çin'de 1980 yılında "tek-çocuk" politikasının uygulamaya girmesinden iki yıl sonra, ultrasonun kitlesel üretimi başlamıştı. Bu süreçte yeni teknoloji minnetle karşılanıyordu. Doğum kontrol teknolojileri ailelerin "istenen sayıda" tek oğul sahibi olmasını sağlarken, bazı eyaletlerde "1,5 çocuk" uygulaması başlatıldı. Bu politika ilk çocuğu kız olan ailelere ikinci çocuğun erkek olma ihtimalini kullanmaları için yürürlüğe girmekteydi. Yazar resmi otoritelerce cinsiyet belirlemenin yasaklanmış olmasına karşın içi para dolu kırmızı zarf ya da bir karton Chunghwa sigarası karşılığında ailelere bebeğin cinsiyetinin bildirildiğini ifade etmektedir. Örneğin, Çin'in Suining kasabasında ultrason teknisyenleri 1.000 Yuan (150 Dolar) karşıllı̆ında bu işi yapmaktadır. Kuşkusuz kız bebeklerin düşük yoluyla yaşamlarının sonlandırılmasına ortam sağlayan bu uygulamanın kısa ve uzun vadeli birçok istenmeyen sonucu bulunmaktadır. Bu koşullarda erkekler için "ikiz erkek bebek" sahibi olmanın ne kadar prestijli olduğunu anlamak hiç de zor değildir. Ne var ki az gelişmiş̧ ülkelerde ailelerin kız çocuklarına da ihtiyaçları vardır. Nitekim yazar onları

1 Amitai Etzioni (1968), "Sex Control, Science and Society", Science, 161 (3846): 1107-1112.

2 Amartya Sen (1990), More Than 100 Million Women Are Missing (NewYork Review of Book Archives) http://www.mybooks.com/articles/1990/12/20/morethan-100-million-women-are-missing/

3 http://www.itsagirlmovie.com/ 
kardeşlerine bakan ve büyüten olarak kodlayan "küçük anne" rollerine vurgu yapmakta, erkek kardeşlerle ablalar arasındaki yaş farkına bu yönden dikkat çekmektedir.

Hvistendahl, Çin'de doğumda cinsiyet dağılımının bölgesel olarak değişebildiğini hatırlatmakta, örneğin, devlet istatistik raporu da Lianyungang şehrinde 5 yaş altında 163 erkek çocuğa 100 kız çocuk düştüğünü belirtmektedir. $\mathrm{Bu}$ durum uzun vadede kız çocukların eş bulma sıkıntıları olmamasına karşın, erkekler için önemli bir eş kıtlığ ile karşılaşacakları anlamına gelmektedir. Nitekim yazar kitabın ilerleyen bölümlerinde bu durumun toplumsal, ekonomik, etik ve hukuki boyutlarını detaylı biçimde incelemektedir.

Üreme hakları aktivistleri bir yandan erkeklerin ekonomik ve sosyal eşitsizliklerin yaratılmasındaki rolünü vurgularken diğer yandan yaratılan rant alanının nasıl işlediğini ortaya koymaktadırlar. Örneğin, Hindistan'da 10 bebekten 7'si yenidoğan servisinde hayata gelmektedir. Apollo Hastanesi'nde görevli Dr. Bedi bu bebeklerin düşükle yok edilen kız bebeklerle yer değiştirdiğini bilerek doğumları yaptırmaktadır. Doktor tıbbi nedenlerle kürtajı desteklediğini ifade ederken, cinsiyet eleme amaçlı kürtaj yapmadığı için Delhi'deki doktorlardan daha az kazandığını da aktarmaktadır. Yazar doğum öncesi yeni tanı yöntemlerinin, doğum kontrol teknolojilerinin "kalite "sözcüğü ile örtüştürülerek tüketiciye sunulduğunu eleştirel üslupla aktarmaktadır. Hvistendahl hastanın tüketici olduğu anlayışıyla birlikte rant alanlarının değişmesinde ultrason ve benzeri teknolojilerin ataerkil değerlerin yaşadığ 1 toplumun hizmetine sunulması arasındaki ilişkiye dikkat çekmektedir.

Malthus'un kuramından hareketle dünya nüfus artışını tehdit olarak gören batılı bilim insanlarının bu tehdidi ortadan kaldırmak için önerisi, bazı ülkelerde doğum oranlarının düşürülmesi olmuştur. Örneğin, Stanford Üniversitesi'nden Dr. Paul R. Ehrlich "The Population Bomb" $(1968)^{4}$ adlı çok satan kitabının ilk bölümünde, Hindistan'a yaptığı gezide gözlemlediği nüfus yoğunluğunun kendisinde yarattığı korkudan söz etmekte, hatta Amerikalıların bile tek çocukla yetinmesi gerektiğine işaret etmekteydi. Hvistendahl, 1958 yılında ABD'nin bu bakış açısını Asya ülkelerine dayatan nüfus politikalarının yürürlüğe konulması için askeri görevlilerin Başkan Eisenhoover tarafindan Asya'nın artan nüfusunu değerlendirme komisyonunun başına getirildiğine dikkat çekmektedir. Yazar, bu politikalarının "yoksullukla mücadele aracı" söylemiyle oldukça başarılı sonuçlar elde ettiğini de belirtmektedir. Örneğin,

4 Paul R. Ehrlich, The Population Bomb, http://staff.washington.edu/jhannah/geog270aut07/readings/population/Ehrlich\%20 \%20Population\%20Bomb\%20Ch1.pdf ( 1975 yeni basım). 
Japonya 1955 'e kadar kürtajı \%30-35 oranında artırarak doğum oranlarını düşürmeyi başarmıştır.

Hvistendahl kitabın "kadınsız dünya" başlıklı bölümünde, kadınların dünyaya gelmesini engelleyen uygulamaların, kadınsız dünya yaratmasının ötesinde erkekleri eş bulamamak gibi bir açmazla karşılaştırdığını ortaya koymaktadır. Yazar, bu beklenmeyen sonucun, uygulamalar devam ettiği için 2013'e kadar 10 Çinli erkekten 1'inin eş bulamayacağ erkekten 1'inin eş bulamayacak kadar yükseleceği anlamına geldiğini söylemektedir. Yazarın ifadesiyle "kadın kıtlığı"nın 2045'e kadar bu şekilde süreceği tahmin edilmektedir.

Yazar, Vietnamlı genç Nguyen'in Tayvanlı bir erkeğe eş olmak üzere ailesine ödenen bir meblağ karşılığında nasıl ithal edildiğini anlatmaktadır. Vietnamlı kadınların doğulu erkekler için ideal gelin olarak çok talep gördükleri belirtilmektedir. Tayvanlı simsarlar tarafından bu amaçla hazırlanan "vietnambride" gibi web siteleri oldukça rağbet görmektedir. Özetle, Vietnam umutsuz Doğu Asyalı bekâr erkekler için en popüler eş kaynaklarından birini oluşturan ülkedir. Bu zengin bekârlar Tayland'dan da gelin satın almaktadır. Filipinler, Özbekistan, Rusya ve Kuzey Kore de gelin ihracı bakımından verimli ülkeler olarak sıralanmıştır. Ancak şunu da söylemek gerekir ki çoğu bekâr erkek bu ülkelere gidip gelin alışverişi yapacak mali kaynağa sahip olmayabilmektedir. Bu durumda gelinler sınır komşusu ülkelerde aranmaktadır. 2003'de toplumsal cinsiyet araştırmaları profesörü Christina Gilmartin, evlilik göçmenlerinin sayısının 4 milyona ulaştığını açıklamıştır. Doğu Asya'nın evlilik ajansları tıpkı mektupla gelin siparişi sağlayan Amerikan evlilik servislerinin görevlerini sürdürüyorlar.

Ortaya çıkan bu soruna çözüm getirilmeye çalışı1ırken, başka sorunlar ortaya çıkabilmektedir. Örneğin, bekâr erkeklerin ithal gelin tercih etmeleri durumunda dolandırılmaları da söz konusu olabilmektedir. İnsan kaçakçılı̆̆ 1 yapan çetelerin üyesi durumunda olan genç kadınlar, satış işlemi sonrasında yükümlülüğü yerine getirmeden ortadan kaybolmaktadırlar. Bu tür "kaçak gelin" örneği oldukça fazladır. İthal gelinler 15-20 yaş arasında olup, göçmen statüsünde bulunmakta ve kocalarının dilini ve kültürünü öğrenmek zorunda kalmaktadır. Ajanslar gelinlerin bakire olmalarını temin etmekle yükümlüdür ve bazı ajanslar kadınlara eşlerini bu konuda aldatmalarının nasıl mümkün olacağını da öğretmektedir. Kadınların dörtte biri kocalarının kendilerine eziyet ettiklerini bildirmişlerdir. Diğer yandan insan kaçakçılığının bir biçimi olarak, kadınların kaçırılarak fuhuş tehdidi altında bekâr erkeklerle evlenmeye zorlanması da bir yöntem olarak ortaya çıkmaktadır. Bir günde düzinelerce erkeğe hizmet sunmak yerine biraz yaşı geçkin ve çirkince bir köylüyle evlenmeye rıza göstermek, bu genç kadınlara sunulan tek seçenek olmaktadır. 
$\mathrm{Bu}$ tür bir gelinin satış fiyatının 5.000 Yuan $(670$ dolar $)$ olduğu belirtilmektedir.

Hintli ve Çinli annelerin oğullarına eş bulabilmek için çok çaba gösterdikleri ve gelin satın almaktan başka bir yol bulamadıkları anlaşılmaktadır. Çok yaygın olmasa da ailenin mali olanaklarının yetersiz olması durumunda satın alınan bir gelinin damadın erkek kardeşleriyle de birlikte olmaya zorlanmasının (poliandri) rastlanan bir durum olduğu ifade edilmektedir. Uluslararası Çalışma Örgütü ile Çinli Kadınlar Federasyonu bu tür insan kaçakçılığı ile mücadele etmek üzere işbirliği yapmışlardır. Ancak evlenecek kadın bulabilme ihtiyacının ortaya çıkardığı sorunların çözümünde başarıya ulaşmak çok da mümkün görünmemektedir.

Yazar kitabın sonunda, "bu hikaye Asya'da değil, Los Angeles'ta bitiyor" diyerek Los Angeles'in şöhretli bir doğum kliniğinde müşterilerin (!) \%70'inin çocuğunun cinsiyetini belirlemek amaciyla geldiğini ve bu kliniğin web sayfasinda "istenen bebek cinsiyetinin garantisi" konusunda bilgi verildiğini aktarmaktadır. Suni döllenme yoluyla yapılan müdahalelerde de cinsiyetin tayini konusunda uygulanan yöntem ve teknikler anlatılmaktadır.

Sonuç olarak, kitap irdelediği konu ve alıntı yaptığı kaynaklar dikkate alındığında sadece kadınsız dünya yaratma çabası ve bunun istenmeyen sonuçları üzerine odaklanmamaktadır. 1960'lardan bu yana toplam nüfus artışının dünyayı tehdit ettiği (!) miti üzerinden batılı ülkelerde ortaya çıkan endişenin, doğum öncesi tarama teknolojilerinin nüfusu yüksek ülkelerde yaygınlaştırılmasına dikkat çekilmektedir. Bu tür nüfus planlama tasarruflarının erkek çocuğu daha değerli gören geleneksel kültürlü ülkelerde, kadının dünyaya gelişini engelleyen "yok etme" eylemine nasıl katkıda bulunduğu gözler önüne serilmektedir. Üstelik sorun yalnız bu kadarla kalmamakta, kaybedilen kadın nüfusun yerine ikame edilmek istenen kadınlar ise en acımasız yöntemlerle istenmeyen hayatlara mahkûm edilmektedir. Bugün güney yarım küreden kuzeye, doğudan batıya doğru yasal ve yasal olmayan göçmen girişleri nedeniyle batılı ülkelerin korkularının nasıl kâbusa dönüştüğünü gördüğümüz bu zaman diliminde, kitabın okur için çok daha etkileyici olacağını tahmin etmek hiç de zor değildir.

Prof. Dr. İlkay Saveı

Ankara Üniversitesi Siyasal Bilgiler Fakültesi 